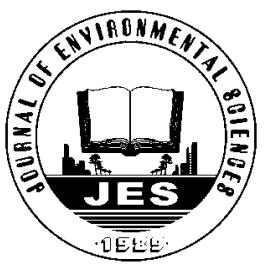

\title{
Risk assessment of Giardia in rivers of southern China based on continuous monitoring
}

\author{
Wei $\mathrm{An}^{1}$, Dongqing Zhang ${ }^{1}$, Shumin Xiao ${ }^{1,2}$, Jianwei $\mathrm{Yu}^{1}$, Min Yang ${ }^{1, *}$ \\ 1. State Key Laboratory of Environmental Aquatic Chemistry, Research Center for Eco-Environmental Sciences, \\ Chinese Academy of Sciences, Beijing 100085, China. E-mail: anwei@rcees.ac.cn \\ 2. College of Emergency Management, Henan Polytechnic University, Jiaozuo 454003, China
}

Received 26 January 2011; revised 07 April 2011; accepted 29 April 2011

\begin{abstract}
The occurrence and risks of Giardia in China have been unclear to date, which has made it difficult to properly manage source water as well as to create reasonable drinking water standards. The levels of Giardia in river networks of several cities in Zhejiang Province, China were found to be in the range of $0-5$ oocysts/10 L in the rainy season in 2008 . The mortality due to Giardia infection for people in this region was calculated to be from 0 to $1.95 \times 10^{-8}$ persons using a conditional probability equation. Based on multiple unboiled water intake routes, the disability-adjusted life years (DALYs) due to Giardia infection for people who consumed conventionally treated water was 0.625 (95\% CI: $0.137-2.05$ ) per $10^{5}$ persons, with the symptom of hospitalization making the highest contribution to total DALYs (0.56 per $10^{5}$ persons; 95\% CI: $\left.0.122-1.84\right)$. The DALYs decreased to 0.425 (95\% CI: $\left.0.137-2.05\right)$ per $10^{5}$ persons per year for those consuming water treated with advanced technology. These values were lower than the acceptable risk $\left(1.97 \times 10^{-5} \mathrm{DALYs}\right.$ per year). This study revealed the risk of Giardia infection to the people in river networks of Zhejiang Province for the first time, and provides a method to evaluate the risk of Giardia infection. The results are useful for the modification of drinking water quality standards based on cost-benefit analysis.
\end{abstract}

Key words: Giardia; risk assessment; water consumption; disability-adjusted life years

DOI: $10.1016 /$ S1001-0742(11)60768-7

\section{Introduction}

Giardiasis infection leading to symptoms including gastroenteritis and abdominal distention is a common waterborne disease in many countries. Giardia can spread between persons and animals through fecal-oral transmission. There are about 2,500,000 cases, or one for every 100 persons per year, in the United States (Rockwell, 2003). In some countries, including China, giardiasis is listed in the drinking water standards.

Several studies have highlighted the health risk assessment of Giardia using the annual individual probability of infection, which has also been used for Cryptosporidium (Jolis et al., 1999; Cummins et al., 2010). Giardia has high infectivity (Gibson et al., 1998), while the symptoms are generally relatively mild comparing with that of Cryptosporidium (US EPA, 1999). Thus, it is impossible to compare their relative risks only based on infection probability. The method of disability-adjusted life years (DALYs) provides a unified assessment measurement using time as a uniform unit (Vijgen et al., 2007) by integrating the different symptoms of adverse health effects (Havelaar et al., 2000), which has been used to assess

\footnotetext{
* Corresponding author. E-mail: yangmin@ rcees.ac.cn
}

the health risk of Giardia. However, previous risk assessments of Giardia have ignored mortality when calculating DALYs (Bennett et al., 1987), which led to the underestimation of risk. In fact, Giardia infection cannot only result in gastroenteritis, abdominal cramps, vomiting, and growth impairment, but also death. In 1982, giardiasis was listed as the underlying cause for four deaths in the United States (US EPA, 1999). Giardiasis can also cause death through complications in malnourished children (Mukherjee and Johnston, 2009) or pneumonia patients (LOPH, 2009). However, mortality from giardiasis is typically underreported in most routine surveillance systems (Vijgen et al., 2007). Thus, there is little information available regarding death caused indirectly by Giardia infection, particularly through gastroenteritis complications.

There are different intake routes of Giardia, including direct consumption, tooth brushing, dishes, and swimming in rivers. However, most previous studies only considered drinking as the exposure route, which can also cause the underestimation of infection risks. In this study, the Giardia concentrations in the source water of several cities of Zhejiang Province, China were continuously monitored during the rainy season of 2008, and then the risk of Giardia infection was calculated by considering the causespecific mortality of fatal gastroenteritis caused by Giardia 
infection and multiple potential exposure routes. The results of this study will be useful for the modification of drinking water quality standards of China.

\section{Materials and methods}

\subsection{Water sampling and Giardia detection}

During the rainy season (June to September) of 2008, samples were collected from the Jiaxing, Yuyao, Tongxiang and Xiaoshan rivers, as shown in Fig. S1 in supporting information. The volume of each sample was ten liters, and the samples were filtered within four hours of sampling. Two samples were collected from the Jiaxing, Yuyao, and Xiaoshan rivers from 8 July to 12 July and on August 29, respectively. In Tongxiang, samples were collected daily from 19 to 29 August.

The detection of Giardia was conducted according to the method described by Hashimoto et al. (2002). The density distribution of the concentration for Giardia was fitted by different probability density functions, i.e. exponential, uniform, lognormal, and normal function using STATISTICA (data analysis software system), version 8.0 (StatSoft, Inc., 2007). Of these, the best goodness-of-fit was selected according to their $p$-value and $\chi^{2}$ test value.

\subsection{Exposure assessment}

The probability of Giardia infection is related to its contamination level in different routes. In this study, three main exposure routes were considered: direct drinking tap water, intake by residues from tooth-brushing and washing, and swallow by swimming in rivers.

The daily consumption of water in China is about 1.75 L per person, while that of other countries generally ranges from 0.25 to $1.1 \mathrm{~L}$ (Teunis et al., 1997; Gale 2001; Hoornstra and Hartog 2003; Westrell et al., 2003; Heyworth et al., 2006; Masago et al., 2006). It should be noted that drinking boiled water and eating heated food is popular in China. In Zhejiang Province, only about $0.8 \%$ of people drink tap water directly (Xu et al., 2008). The ingestion volume from residues, was firstly estimated to be $0.007-0.071 \mathrm{~L} /$ (person-day), including adsorbed water on the mouth after tooth-brushing and food and dish after washing (An et al., 2011). The accidental intake volume of a person swimming in a river was about $0.016-0.037 \mathrm{~L}$ of surface water (Dufour et al., 2006), and about 10.5\%$21.6 \%$ of the population swim in the rivers (Bureau, 2005). The frequency of swimming was assumed to be once a week over a 5-month period from May to September (i.e., 20 times/year). Removal of cysts by conventional treatment waterworks was about $2-2.5 \log _{10}$ units, whereas advanced treatments combining ozone and conventional treatment had an expected efficiency of 4-4.5 $\log _{10}$ units (WHO, 2009).

\subsection{Dose-response of Giardia infection and uncertainty analysis}

The exponential models used to fit the dose-response data of Giardia infection were as Eq. (1):
$P_{\text {in }}=1-\mathrm{e}^{-r \times D}$

where, $P_{\text {in }}$ is the probability of infection; $r$ is a scale factor for the dose, of which the value was 0.01982 with a $95 \%$ confidence interval of 0.009798 to 0.03582 (Rose et al., 1991), and $D$ is the ingested dose of Giardia. The uncertainty analysis in this study included parameter fluctuations, which were conducted by the Monte Carlo method (Crystall Ball 2000 Professional; Decisioneering, USA).

\subsection{Calculation of DALYs}

The adverse effects of contaminants can reduce the length and quality of life. This reduction can be measured by the disability-adjusted life years (DALYs) (Murray and Lopez, 1997). DALYs are the sum of lost life-years (LYL) due to mortality and those lost by living with disability (YLD). YLD can be estimated by Eq. (2):

$\mathrm{YLD}=\sum_{i}^{n} \sum_{j}^{m} \alpha_{j} N_{i} L_{i} W_{j}$

where, $N$ is the number of individuals affected by a nonlethal disease; $L$ is the duration of the disease, and $W$ is the measure of its severity, weighed with a factor between 0 and 1. $\alpha$ represents the portion of individuals with different severities of gastroenteritis. Gastroenteritis due to Giardia was divided into three severities $(j)$ : slight symptoms, i.e. no need to seek treatment (No-GP), need to visit a general practitioner (GP), and hospitalization.

The lost life-years (LYL) were calculated by Eq. (3):

$\mathrm{LYL}=\sum_{i}^{n} d_{i} \mathrm{E}_{i}$

where, $i$ is the age in the special population, $d_{i}$ is the amount of deaths due to the disease at age $i$, and $E_{i}$ is the standard life expectancy at age $i$.

In this study, the mortality rate associated with Giardia infection $\left(P_{\mathrm{f}_{-} \text {giar }}\right)$ was calculated by multiplying the mortality due to gastroenteritis $(\mathrm{P}(\mathrm{f} \mid \mathrm{g}))$ by the incidence of gastroenteritis $\left(P_{\text {in }}\right.$ in Eq. (1) ) caused by Giardia infection. The mortality rate from gastroenteritis $(\mathrm{P}(\mathrm{f} \mid \mathrm{g}))$ can be calculated by the quotient of the probability of fatal gastroenteritis $(\mathrm{P}(\mathrm{f}, \mathrm{g}))$ and the incidence of gastroenteritis $(\mathrm{P}(\mathrm{g}))$ (An et al., 2011).

\section{Results and discussion}

\subsection{Exposure assessment of Giardia}

The frequency density distribution of Giardia in source water of the surveyed region is shown in Fig. 1. The average concentration was found to be 1 oocyst/10 L. The highest concentration of 5 oocysts/10 L was observed once, and zero oocysts/10 L frequently occurred with thirteen times. This level was similar with the results of previous studies. For example, the concentration of 


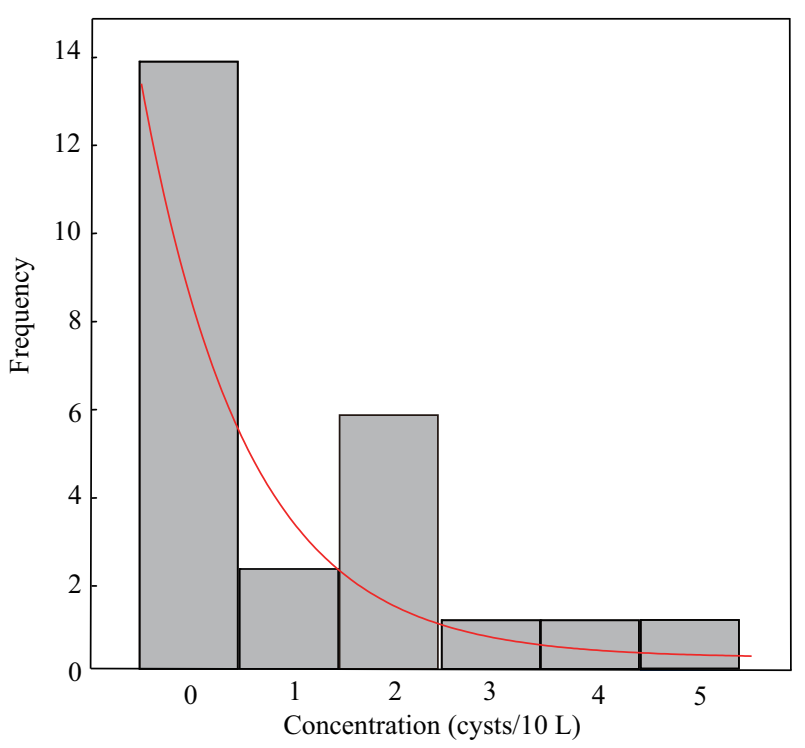

Fig. 1 Frequency distribution for Giardia in $10 \mathrm{~L}$ of surface water.

Giardia cysts were detected to be from 0.03 to 10 cysts $/ 10$ L with in 26\%-92\% raw water of Japan and United States (Rose et al., 1991; Hashimoto et al., 2002). Much higher concentration was found from 1 to 125 cysts/10 L in rivers of Chengdu and Guangzhou, China (Cai et al., 2008; Wang et al., 2008).

Exponential distribution models were used to fit the levels of Giardia (Fig. 1), and the lowest $\chi^{2}$ test value observed was $3.584(p=0.05832)$. Equation (4) was used to describe the probability distribution of Giardia in the investigated region:

$\operatorname{Pr}\left(C_{\text {cry }}\right)=0.99 \times \mathrm{e}^{-0.99 \times C_{\text {giar }}}$

where, $\operatorname{Pr}$ is the probability distribution of Giardia occurrence and $C_{\text {giar }}$ (count/10 L) is the concentration of Giardia. The annual dose $\left(D_{\mathrm{a}}\right)$ can be calculated by Eq. (5).

$D_{\mathrm{a}}=C_{\text {giar }} \times \phi \times V_{\mathrm{d}} \times T$

where, $\phi(\%)$ is the Giardia removal efficiency in drinking water treatment, $T$ (day) is the duration at a Giardia exposure, and $V_{\mathrm{d}}(\mathrm{L} /($ day·person $))$ is the daily intake volume of water (An et al., 2011).

\subsection{Mortality caused by Giardia}

The major symptom of giardiasis is gastroenteritis, which can induce death by complications such as dehydration, hypernatraemia, and hypophosphataemia. The mortality $\left(P_{\mathrm{f}_{-} \text {giar }}\right)$ induced by gastroenteritis for Giardia infection was estimated based on the cause-specific mortality as Eq. (6):

$P_{\mathrm{f}_{\text {giar }}}=\frac{\mathrm{P}(\mathrm{f}, \mathrm{g})}{\mathrm{P}(\mathrm{g})} \times\left(1-\mathrm{e}^{-0.01982 \times D}\right)$

where, fatal gastroenteritis $(\mathrm{P}(\mathrm{f}, \mathrm{g}))$ was reported in Yearbook of Health in the People's Republic of China ( $\mathrm{Li}$ and $\mathrm{Hu}, 2007)$ as shown in Table $\mathrm{S} 1$ in supporting information and incidence of gastroenteritis $(\mathrm{P}(\mathrm{g}))$ in China is as previously reported to be 56.7 per $10^{5}$ persons (Lin and Dong, 2008). However, it should be noted that the estimated risk could be higher than the actual one since Giardia infection is only one of several factors reasons responsible for gastroenteritis.

\subsection{DALY calculation for different scenarios}

In the investigated region, both the conventional and advanced treatments, which have different Giardia removal efficiencies, were adopted for drinking water purification. The removal efficiency for the conventional treatment was $2 \log -2.5 \log$, while that for advanced treatment is 4log-4.5log (Rockwell, 2003; WHO, 2009). As shown in Table 1, under the conventional treatment, the total DALYs were 0.625 per $10^{5}$ persons (95\% CI: $0.137-2.05$ per $10^{5}$ person) using Eqs. (1)-(6), which is much lower than the average DALYs for gastroenteritis diseases in China in 2004 (324 per $10^{5}$ persons) (WHO, 2004). These findings indicate that Giardia infection contributes to about $0.19 \%(0.625 / 324)$ of gastroenteritis diseases in Zhejiang Province.

The acceptable lifetime cancer risk is $10^{-4}$ to $10^{-6}$ (Health Canada, 2004), which could be converted into a tolerable annual loss of DALYs of $1.97 \times 10^{-7}$ to $1.97 \times$ $10^{-5}$ based on a 70-year lifespan considering the average DALYs per cancer death is 13.8 years (Havelaar and Melse 2003). Thus, the health risk due to Giardia infection was acceptable from surface water exposure under conventional treatment in this region.

As shown in Fig. 2, the highest contribution of symptoms to total DALYs was the hospital, followed by GP. The contribution from fatalities was very low. The DALY of swimming in rivers was 0.426 with a $95 \%$ CI range of 0.031 to 1.83 , showing that the exposure route of swimming contributed $79.5 \%$ to the total DALYs. It is interesting that the contribution from the route of direct consumption was only $6.1 \%$ (DALY, 0.0381 ; 95\% CI: 2.64 $\times 10^{-3}-0.189$ ), as shown in Table 1 . As shown in Fig. 3, the health risk only decreased slightly represented by the diameter of pies when advanced treatment was used. Since the major risk contribution came from swimming in rivers, improving the water purification process could not lead

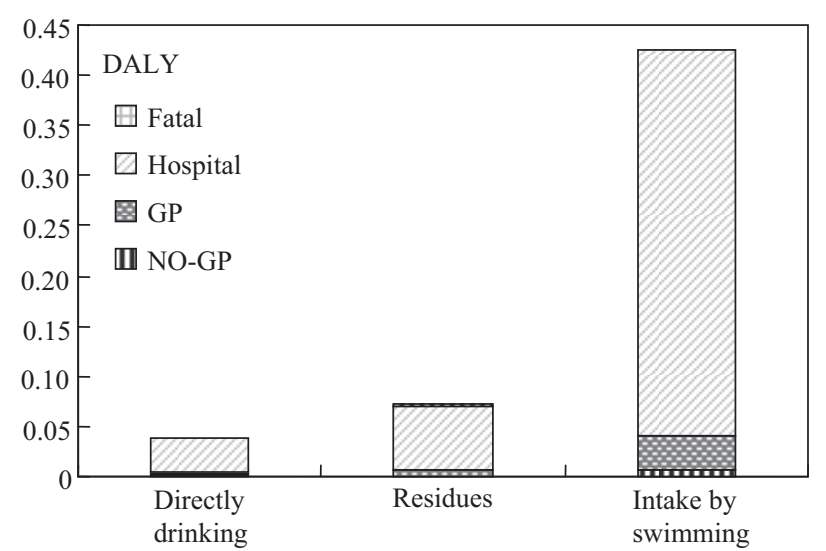

Fig. 2 DALYs for different exposure routes with different symptoms. NO-GP: no need to visit a general practitioner; GP: visited a general practitioner. 
Table 1 Disability-adjusted life years (DALYs) per $10^{5}$ persons of different routes with different treatments

\begin{tabular}{|c|c|c|c|c|c|}
\hline Routes & & $\begin{array}{l}\text { Directly drinking } \\
\text { tap water }\left(\times 10^{-3}\right)\end{array}$ & $\begin{array}{l}\text { Intaked by } \\
\text { residues }\left(\times 10^{-3}\right)\end{array}$ & $\begin{array}{l}\text { Swallowed by } \\
\text { swimming }\left(\times 10^{-3}\right)\end{array}$ & $\begin{array}{l}\text { Sum } \\
\left(\times 10^{-3}\right)\end{array}$ \\
\hline \multirow[t]{5}{*}{ Conventional treatment } & NO-GP & $\begin{array}{l}0.565 \\
(0.0392-2.8)\end{array}$ & $\begin{array}{l}1.05 \\
(0.0654-6.34)\end{array}$ & $\begin{array}{l}5.98 \\
(0.43-25.6)\end{array}$ & $\begin{array}{l}8.91 \\
(1.98-28.9)\end{array}$ \\
\hline & GP & $\begin{array}{l}3.05 \\
(0.212-1.51)\end{array}$ & $\begin{array}{l}5.72 \\
(0.354-34.5)\end{array}$ & $\begin{array}{l}35.5 \\
(2.51-150)\end{array}$ & $\begin{array}{l}50.9 \\
(11.0-168)\end{array}$ \\
\hline & Hosp. & $\begin{array}{l}33.8 \\
(2.34-167)\end{array}$ & $\begin{array}{l}63.8 \\
(3.94-386)\end{array}$ & $\begin{array}{l}383 \\
(27.6-1674)\end{array}$ & $560(122-1840)$ \\
\hline & Fatal & $\begin{array}{l}0.733 \\
(0.0508-3.63)\end{array}$ & $\begin{array}{l}0.941 \\
(0.0658-4.72)\end{array}$ & $\begin{array}{l}1.52 \\
(0.109-6.54)\end{array}$ & $4.18(1.19-10.6)$ \\
\hline & Sum & $\begin{array}{l}38.1 \\
(2.64-189)\end{array}$ & $\begin{array}{l}71.5 \\
(4.43-430)\end{array}$ & $\begin{array}{l}426 \\
(31-1830)\end{array}$ & $\begin{array}{l}625 \\
(137-2050)\end{array}$ \\
\hline \multirow[t]{5}{*}{ Advanced treatment } & NO-GP & $0.00551\left(3.66 \times 10^{-4}-0.0309\right)$ & $0.0124\left(7.75 \times 10^{-4}-0.0782\right)$ & $\begin{array}{l}6.03 \\
(0.448-26)\end{array}$ & $6.06(0.48-260)$ \\
\hline & GP & $\begin{array}{l}0.0297 \\
\left(1.98 \times 10^{-3}-0.0167\right)\end{array}$ & $0.0676\left(4.19 \times 10^{-3}-0.426\right)$ & $\begin{array}{l}35.3 \\
(2.62-152)\end{array}$ & $35.5(2.8-152)$ \\
\hline & Hosp. & $0.329(0.0219-1.85)$ & $0.754(0.0466-4.77)$ & $\begin{array}{l}386 \\
(2.87-1670)\end{array}$ & $389(30.7-1670)$ \\
\hline & Fatal & $\begin{array}{l}7.14 \times 10^{-3} \\
\left(4.75 \times 10^{-4}-0.04\right)\end{array}$ & $\begin{array}{l}0.0112 \\
\left(7.79 \times 10^{-4}-0.0584\right)\end{array}$ & $\begin{array}{l}1.53 \\
(0.114-6.63)\end{array}$ & $1.56(0.144-6.66)$ \\
\hline & Sum & $\begin{array}{l}0.372 \\
(0.0247-2.08)\end{array}$ & $\begin{array}{l}0.845 \\
(0.0525-5.33)\end{array}$ & $\begin{array}{l}429 \\
(32-1850)\end{array}$ & $\begin{array}{l}432 \\
(34-1850)\end{array}$ \\
\hline
\end{tabular}

Results expressed as median (95\% CI), where the sums are not simple the accumulation of medians in all rows or columns, but medians of summing the simulation all rows or columns using Crystal Ball software.

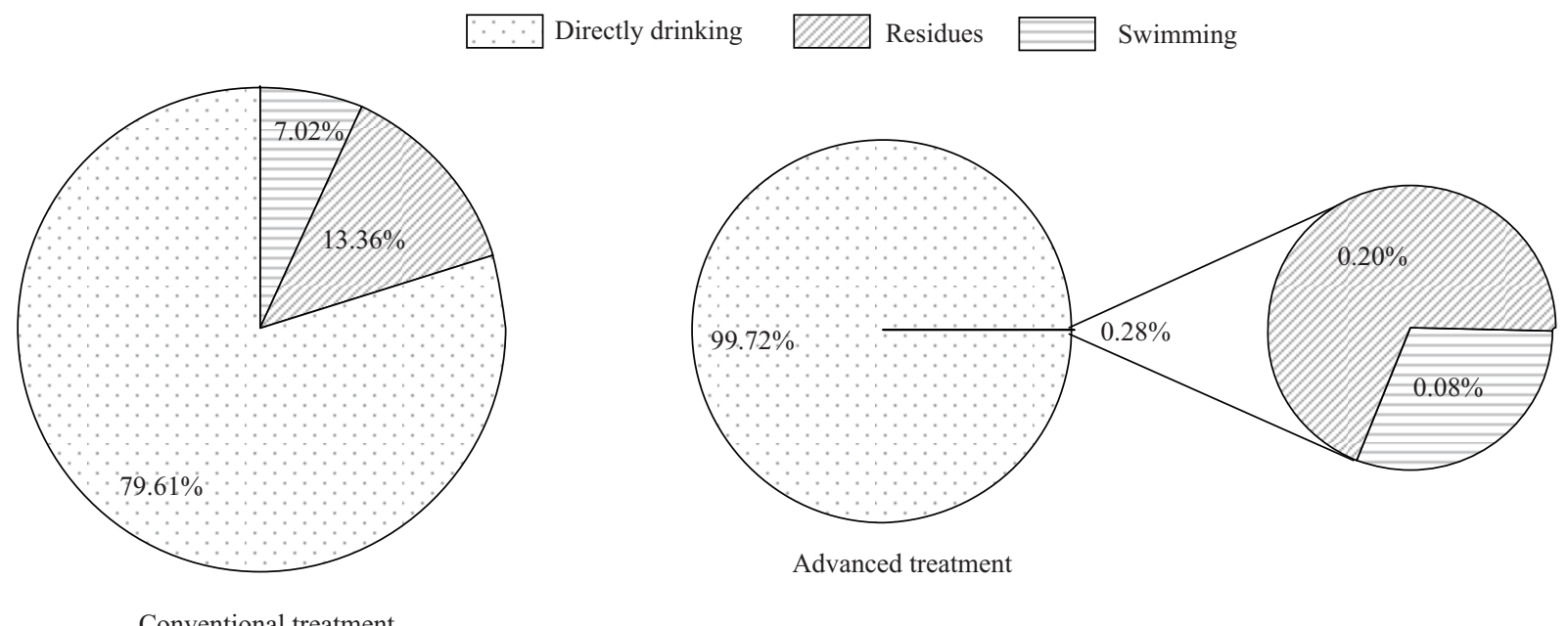

Fig. 3 Contribution to total DALYs from different exposure routes because of Giardia infection through conventional and advanced water treatment, respectively.

to a significant reduction of the risk caused by Giardia infection.

The DALY for Giardia from water and food in the Netherlands was 364 in a population of about 16.4 million (Vijgen et al., 2007), which was equivalent to 2.2 DALYs per $10^{5}$ person-years, and much higher than our result ( 0.625 per $10^{5}$ person-years) from the water exposure route. This was likely related to the habits of drinking boiled water and eating cooked food, because Giardia cysts are highly susceptible to heat (Rockwell, 2003).

\section{Conclusions}

The following conclusions can be drawn. The average concentration of Giardia oocysts in the river network area of Zhejiang Province, China was 1 cyst per $10 \mathrm{~L}$, which was in accordance with most previous studies. Due to Chinese water consumption habits, the DALY for people in the region was 0.625 per $10^{5}$ person-years, which was in the acceptable level. Swimming in rivers was the major health risk source of Giardia infection. This study provides a method to establish the risk of Giardia infection, which is useful for the modification of water quality standards based on cost-benefit analysis.

\section{Acknowledgments}

This work was supported by the Foundation of Major Science and Technology Program for Water Pollution Control and Treatment (No. 2009ZX07419-002) and the National Natural Science Foundation of China (No. 50778171, 50809066, 20807013).

\section{Supporting materials}

Sampling sites map and fatal-gastro probability $\mathrm{P}(\mathrm{f}, \mathrm{g})$ associated with this article can be found in the online version. 


\section{References}

An W, Zhang D Q, Xiao S M, Yu J W, Yang M, 2011. Quantitative health risk assessment of Cryptosporidium in rivers of southern china based on continuous monitoring. Environmental Science and Technology, 45(11): 4951-4958.

Bennett J V, Holmberg S D, Rogers M F, Solomon S L, 1987. Infectious and parasitic diseases. In: Closing the Gap: The Burden of Unnecessary Illness (Amler R W, Dull H B, eds.). Oxford University Press, New York.

Bureau Z P C S, 2005. Swimming status and development strategy in school of Zhejiang Province. Retrieved June 24th, 2010. http://tyj.zj.gov.cn/article/detail/2731.shtml.

Cai J, Ye J, Du H L, Hu X W, Liu J, Huang W et al., 2008. Investigation of Cryptosporidium and Giardia contaminating drinking-water in Chengdu. Chinese Journal of Health Laboratory Technology, 17(12): 2165-2167.

Cummins E, Kennedy R, Cormican M, 2010. Quantitative risk assessment of Cryptosporidium in tap water in Ireland. The Science of the Total Environment, 408(4): 740-753.

Dufour A P, Evans O, Behymer T D, Cantú R, 2006. Water ingestion during swimming activities in a pool: A pilot study. Journal of Water and Health, 4(4): 425-430.

Gale P, 2001. Developments in microbiological risk assessment for drinking water. Journal of Applied Microbiology, 91(2): 191-205.

Gibson C J III, Haas C N, Rose J B, 1998. Risk assessment of waterborne protozoa: current status and future trends. Parasitology, 117: S205-S212.

Hashimoto A, Kunikane S, Hirata T, 2002. Prevalence of Cryptosporidium oocysts and Giardia cysts in the drinking water supply in Japan. Water Research, 36(3): 519-526.

Havelaar A H, De Hollander A E, Teunis P F, Evers E G, Van Kranen H J, Versteegh J F et al., 2000. Balancing the risks and benefits of drinking water disinfection: disability adjusted life-years on the scale. Environ Health Perspect, 108(4): 315-321.

Havelaar A H, Melse J M, 2003. Quantifying public health risks in the WHO guidelines for drinking-water quality: a burden of disease approach. Bilthoven, World Health Organization.

Health Canada, 2004. Federal contaminated site risk assessment in Canada part I: guidance on human health preliminary quantitative risk assessment (PQRA).

Heyworth J S, Glonek G, Maynard E J, Baghurst P A, FinlayJones J, 2006. Consumption of untreated tank rainwater and gastroenteritis among young children in South Australia. International Journal of Epidemiology, 35(4): 1051-1058.

Hoornstra E, Hartog B, 2003. A quantitative risk assessment on Cryptosporidium in food and water. Retrieved April 10, 2010. http:// www.teagasc.ie/publications/2003/conferences/cryptosporidiumparvum/paper05.asp.

Jolis D, Pitt P, Hirano R, 1999. Risk assessment for Cryptosporidium parvum in reclaimed water. Water Research, 33(13):
3051-3055.

Li Y, Hu G C, 2007. Year Book of Health in the People's Republic of China. People's Medical Publishing House.

Lin M, Dong B Q, 2008. Status in epidemiological research of infectious diarrhea. China Tropical Medicine, 8(4): 675677.

LOPH (Louisiana Office of Public Health), 2009. Infectious disease epidemiology section annual report. Giardiasis is a class $\mathrm{c}$ disease and must be reported to the state within five business days. Louisiana Office of Public Health, Baton Rouge, LA.

Masago Y, Katayama H, Watanabe T, Haramoto E, Hashimoto A, Omura T et al., 2006. Quantitative risk assessment of noroviruses in drinking water based on qualitative data in Japan. Environmental Science and Technology, 40(23): 7428-7433.

Mukherjee S, Johnston M H, 2009. Giardiasis, WebMD Health Professional Network.

Murray C J, Lopez A D, 1997. Global mortality, disability, and the contribution of risk factors: Global burden of disease study. Lancet, 349(9063): 1436-1442.

Rockwell R L, 2003. Giardia lamblia and giardiasis with particular attention to the Sierra Nevada. http://www.ridgenet.net/ rockwell/Giardia.pdf.

Rose J B, Haas C N, Regli S, 1991. Risk assessment and control of waterborne giardiasis. American Journal of Public Health, 81(6): 709-713.

Teunis P F M, Medema G J, Kruidenier L, Havelaar A H, 1997. Assessment of the risk of infection by Cryptosporidium or Giardia in drinking water from a surface water source. Water Research, 31(6): 1333-1346.

Vijgen S M C, Mangen M J M, Kortbeek L M, van Duijnhoven Y T H P, Havelaar A H, 2007. Disease Burden and Related Costs of Cryptosporidiosis and Giardiasis in the Netherlands. Bilthoven, Netherland, National Institute for Public Health and the Environment (RIVM).

US EPA, 1999. Giardia: Drinking Water Health Advisory. Environmental Protection Agency, Washington, United States.

Wang H T, Chen L F, Zheng F, Dong Y L, 2008. Investigation on certain river and water treatment by Giardia and Cryptosporidium. Guangzhou Chemical Industry, 36(1): 51-60.

Westrell T, Bergstedt O, Stenström T A, Ashbolt N J, 2003. A theoretical approach to assess microbial risks due to failures in drinking water systems. International Journal of Environmental Health Research, 13(2): 181-197.

WHO (World Health Organization), 2004. The Global Burden of Disease 2004 Update. ISBN: 9789241563710.

WHO (World Health Organization), 2009. Risk assessment of Cryptosporidium in drinking water: 143. http://whqlibdoc. who.int/hq/2009/WHO_HSE_WSH_09.04_eng.pdf

Xu P, Huang S B, Wang Z J, Gustavo L, 2008. Water consumption habit in general population of Shanghai and Beijing, China. Asian Journal of Ecotoxicology, 3(3): 224-230. 
Risk assessment of Giardia in rivers of southern China based on continuous monitoring

\section{Supporting materials}

Table S1 Parameter values of fatal-gastro probability P(f,g) at different ages ( $\mathrm{Li}$ and $\mathrm{Hu}, 2007)$

\begin{tabular}{lllll}
\hline Age & $\bar{S}\left(\times 10^{4}\right)$ & $\mathrm{P}(\mathrm{f}, \mathrm{g})\left(10^{-5}\right)$ & Age & $\bar{S}\left(\times 10^{4}\right)$ \\
\hline$<1$ & 3808 & 0.83 & $50-54$ & 6330 \\
$1-4$ & 3090 & 0.15 & $55-59$ & 4637 \\
$5-9$ & 9015 & 0 & $60-64$ & 4170 \\
$10-14$ & 12540 & 0 & $65-69$ & 3478 \\
$15-19$ & 10303 & 0 & $70-74$ & 2557 \\
$20-24$ & 9457 & 0 & $75-79$ & 0.04 \\
$25-29$ & 11760 & 0 & $80-84$ & 0.06 \\
$30-34$ & 12731 & 0.03 & $85-89$ & 0.07 \\
$35-39$ & 10915 & 0.03 & $90-94$ & 303 \\
$40-44$ & 8124 & 0 & $95-99$ & 0.31 \\
$45-49$ & 8552 & 0.06 & $100+$ & 0.36 \\
\hline
\end{tabular}

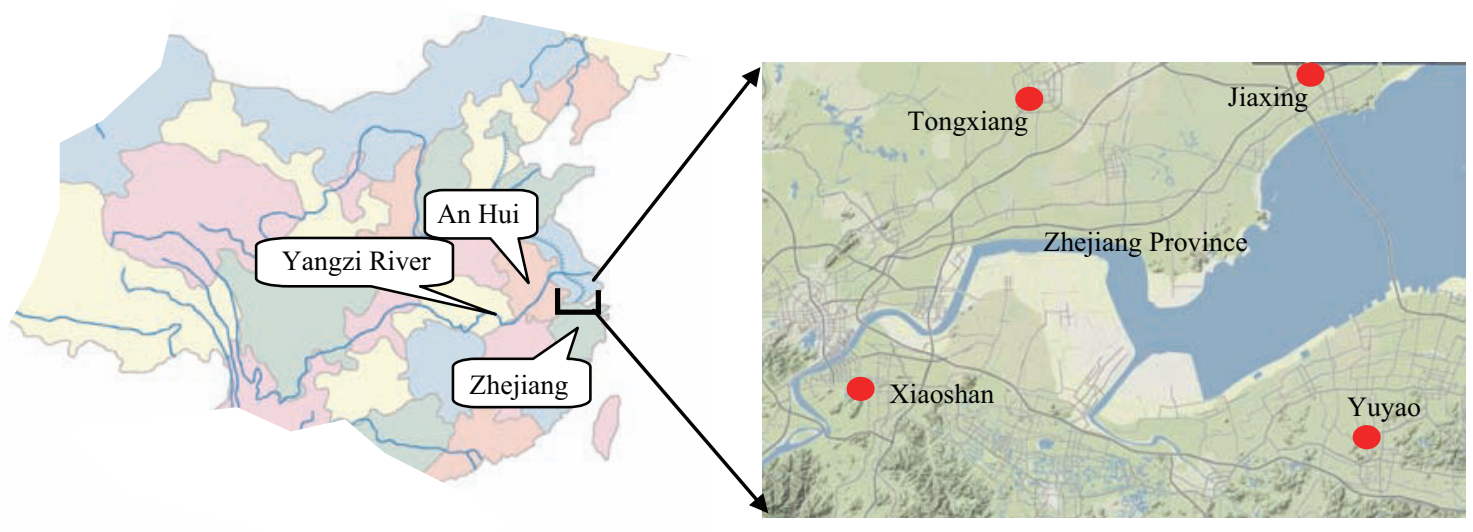

Fig. S1 Sampling sites (red cycle) of rivers that are used as sources for drinking water plants. This map was cited from reference (An et al., 2011). 